\title{
Determining Optimal Corporate Capital Structure
}

Clark T. Benson, (Email: clarkbenson@comcast.net ), National Security Agency, Maryland Franklin Lowenthal, (Email: flowenthal@bay.csuhayward.edu), California State University, Hayward

\begin{abstract}
This paper considers the mathematical relationship between two variables: independent variable is corporate debt as a percentage of corporate assets while the dependent variable is the present value of the tax savings on the interest paid on the corporate debt. We examine this relationship for any fixed number of future states under the Cox-Rubinstein model. The functional relationship is a sawtooth function with a discrete set of discontinuities. By examining the behavior of this function we find that there is for each number of states always a unique debt to asset percentage between 0 and $100 \%$ for which the present value of the tax savings is a maximum.
\end{abstract}

\section{INTRODUCTION}

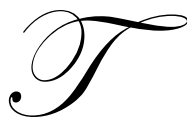

he capital structure of a corporation consists of long-term debt and shareholder equity. Long-term debt is usually issued as a bond with a stated maturity and a promised interest to be paid in addition to the principal. The bond is a contractual liability arrangement between the corporation and the bondholder. If the contractual cannot be paid in full at maturity, then the corporation is in technical bankruptcy and the bondholder has the right to claim the residual assets of the firm.

Let $\mathrm{B}$ be the value of the claim of the bondholder, and let $\mathrm{D}$ be the market value of the debt; then $\mathrm{B}=$ $\min (\mathrm{D}, \mathrm{A})$ where $\mathrm{A}$ is the market value of the residual assets. $\mathrm{B}$ is a contingent claim on the assets of the firm. On the other hand, shareholders who have purchased shares as equity in the corporation have no contractual arrangement and have a lower priority than the bondholder in the order of contingent claims on the assets of the firm. The market value of the claim of the shareholder is given by $\mathrm{E}=\max (\mathrm{A}-\mathrm{D}, 0)$. In particular if $\mathrm{D}$ is greater than $\mathrm{A}$ then the shareholder claim is valueless. However, there is limited liability so that the most a shareholder can lose in the eventuality of bankruptcy is the original investment. Moreover, it clearly is to the benefit of the shareholder to see to it that the market value of the assets is as high as possible.

Under current corporate law, the interest paid on debt is deducted as an expense before taxes are paid; thus it acts as a tax shield. This remains true as long as the corporation is in a taxable status. If the corporation has defaulted on its debt and is in technical bankruptcy, there is no tax and therefore no tax shield for the interest paid on corporate debt. Now the present value of the tax shield (PVTS) is simply:

\section{PVTS $=$ tax rate $*$ debt $*$ interest rate $/$ discount rate;}

If the appropriate discount rate is the same as the interest rate on the bonds then this simplifies to:

\section{PVTS $=$ tax rate $*$ debt}

This PVTS is an asset that accrues to the benefit of the shareholder.

At first glance it would appear that if PVTS is so valuable then the higher the debt, the better it would be for the shareholder. However, it is common sense that at some point the amount of debt poses a threat to the viability of the firm. There is a positive probability that the future market value of the assets will not exceed the debt. Hence there 
exists a balance between the desire for a large tax shield and the threat of financial distress. This balance should lead to an optimal capital structure of the business firm.

Almost 50 years ago, Modigliani and Miller showed that the market value of the assets of a corporation is equal to the sum of the market value of its equity and the market value of its debt. They asserted further that as long as the interest paid on debt yields a savings on taxes, then the market value of the assets of the firm is increased with an increase in corporate debt. Of course, this assumes that the corporation is a viable entity (not in bankruptcy) and has net income that it needs to shield from taxes. However, the tax savings cannot be a linear function of the debt to asset ratio since at some point the debt load would become so great as to force the corporation to default.

In a previous paper, the authors expanded on Merton's demonstration that corporate debt and corporate equity are really options on the assets of the firm and thus behave according to the option pricing theories. One version of options pricing formulated by Cox, Ross and Rubinstein is to view this process as simply a binomial random process over time. By dividing time into a fixed number of discrete steps, it is shown that at each node the value of the assets moves up or down according to a binomial distribution whose parameter is a function of time, volatility and the rate of return. It is known that in the limit as the number of states approaches infinity, this model converges to the continuous time partial differential equation model of Merton. The advantage of the binomial model lies in its simplicity and the ability to explicitly calculate the probability of each terminal state.

We shall simplify the exposition by assuming that the corporate debt consists of a single bond whose interest and principal are to be paid at maturity, i.e. a zero-coupon bond. For example, suppose that a firm has assets currently having a market value of 100 and a bond with par value of 50 and a promised payment of 67.49 to be made 5 years from now. Under a certain set of parameters, the probability that assets 5 years from now are at least equal to the promised payment of 67.49 is calculated to be $80 \%$. The tax savings under a no default condition and a $40 \%$ marginal tax rate is $50 * .4=20$ while the expected tax savings with a $20 \%$ probability of default is only $50 * .4 * .8=16$. We wish to study this expected value of the net present value of the tax savings as a function of the debt to asset ratio of the firm $(0.50=50 / 100$ in the example). This will require us to calculate the probability that the assets of the firm at the time the promised payment is due will equal or exceed the promised payment (.80 in the example); this will insure that the firm is viable, i.e. not in default on its debt. We assume in that case that there is sufficient income to exceed the amount of the tax shield.

\section{BINOMIAL FORMULAS OF COX-RUBINSTEIN DISCRETE TIME MODEL}

We will show in this section how to use the Cox-Rubinstein formulas to determine when a bond is just in default (Rubinstein was more generally interested in finding the present value of a call option). We will follow their presentation which has terminal states arrayed from all down in terminal state 0 to all up in terminal $n+1$ (where the time interval $t$ is partitioned into $\mathrm{n}$ subintervals). $\sigma$ will be used to represent the volatility (usually between .10 and .25) while $R$ will represent the riskless rate of return. We denote by $S$ the current market value of the assets of the firm and by $\mathrm{D}$ the par value of the corporate debt; then $\mathrm{D}$ will vary in the closed interval from 0 to $\mathrm{S}$ so that the debt to asset ratio $\mathrm{D} / \mathrm{S}$ can vary from 0 to 1.

We then will use the following formulas:

$$
\begin{aligned}
& \mathrm{K}=\mathrm{D} * \exp (\mathrm{R} * \mathrm{t}) \\
& \mathrm{Up}=\exp \left(\sigma^{*} \operatorname{sqrt}(\mathrm{t} / \mathrm{n})\right) ; \text { Down }=1 / \mathrm{Up} \\
& \mathrm{Rate}=(\mathrm{R}+1)^{\wedge}(\mathrm{t} / \mathrm{n}) ; \mathrm{q}=(\text { Rate }- \text { Down }) /(\mathrm{Up}-\text { Down }) \\
& \mathrm{A}=[\ln (\mathrm{K})-\ln (\mathrm{S})-\mathrm{n} * \ln (\text { Down })] /[\ln (\mathrm{Up})-\ln (\text { Down })] ; \\
& \text { ceil }(\mathrm{A})=\text { smallest integer that is greater than or equal to A }
\end{aligned}
$$

$\mathrm{K}$ represents the total promised payment (principal $\mathrm{D}+$ interest at rate $\mathrm{R}$ ) to the bondholders after $\mathrm{t}$ years. Up represents the factor that the assets of a firm with volatility $\sigma$ may increase by during one period when the time 
interval $\mathrm{t}$ is partitioned into $\mathrm{n}$ equal length subintervals; Down $=1$ / Up represents the factor by which the assets may decrease in one period. The parameter of the underlying binomial random process is given by the variable q; it represents the probability of a success (Up) during one trial or period. The key computation is to find the value of ceil(A); this integer represents the minimum number of successes (Up) in $n$ trials of the binomial distribution such that the market value of the assets of the firm with an initial value of $S$ at time $t=0$ (present) will have a value after time $t$ years that will be greater than or equal to the amount of the promised payment $\mathrm{K}$ to bondholders at that time (the variable A represents the value at which exact equality occurs). Hence the probability that the firm is not in default is simply the probability that the number of successes will equal or exceed ceil(A). This is the same as subtracting the cumulative distribution function of the binomial distribution evaluated at ceil(A) -1 from one.

For example, with $\mathrm{S}=100, \mathrm{D}=40, \mathrm{R}=.05, \mathrm{t}=5$ years and $\mathrm{n}=100$ we find that $\mathrm{K}=51.361$, $\mathrm{Up}=1.057$, Down $=.946, \mathrm{q}=.508, \mathrm{~A}=44.041$ so that $\operatorname{ceil}(\mathrm{A})=45$. Then the sum of the binomial probabilities from 45 to 100 is 0.896 which represents the probability that the firm will not default on the promised payment of 51.361 in 5 years hence. With a $40 \%$ marginal tax rate the expected value of the present value of the tax savings on the bond interest is simply the product of $40 * .4 * .896=14.336$.

Clearly as the variable $\mathrm{D}$, the par value of the bonds is allowed to increase from 0 to $\mathrm{S}$, the current market value of the assets of the firm, the variable ceil(A) increases so that the probability of default increases as it must; since the marginal tax rate is a constant, the expected value of the present value of the tax savings is a product of two terms where the probability of not being in default decreases as the debt $\mathrm{D}$ increases. Is there a unique value of $\mathrm{D}, 0<$ $\mathrm{D}<\mathrm{S}$, for which this product assumes a maximum value? The key to understanding the nature of the problem that we are formulating is to understand that our function has a discrete set of discontinuities at those values of D for which ceil(A) jumps to the next integer. At such points the probability of default has a jump discontinuity since the cumulative distribution function of a discrete probability distribution is just a simple step function.

\section{DETERMINATION OF OPTIMAL CORPORATE DEBT TO ASSET RATIO}

We assume that the partition size $\mathrm{n}$ remains fixed; we do not investigate the behavior of the optimal debt to asset ratio as the partition size $\mathrm{n}$ approaches infinity.

We wish to determine the values of $\mathrm{D}$ for which $\mathrm{A}=\operatorname{ceil}(\mathrm{A})$, i.e. for which $\mathrm{A}$ is an integer. As $\mathrm{D}$ varies, the change in $\mathrm{A}$ is entirely due to the change in

$\ln (\mathrm{K})=\ln (\mathrm{D})+\mathrm{R} * \mathrm{t}$

If $\mathrm{D}[\mathrm{k}]$ and $\mathrm{D}[\mathrm{k}+1]$ are successive values of $\mathrm{D}$ for which the cumulative distribution function is discontinuous, then since ceil(A) must differ by exactly one, we have that

$[\ln (\mathrm{D}[\mathrm{k}+1])-\ln (\mathrm{D}[\mathrm{k}])] /[\ln (\mathrm{Up})-\ln ($ Down $)]=1$ or

$\ln (\mathrm{D}[\mathrm{k}+1] / \mathrm{D}[\mathrm{k}])=\ln (\mathrm{Up} /$ Down $)$ or since $\mathrm{Up} /$ Down $=\mathrm{Up}^{\wedge} 2$

$\mathrm{D}[\mathrm{k}+1]=\mathrm{D}[\mathrm{k}] * \mathrm{Up} \wedge 2$.

Now the function we are studying, namely the expected value of the present value of the tax savings, is a saw-tooth function with each point of discontinuity representing a local maximum. At the point of discontinuity, the function falls by an amount equal to the product of the debt and the single appropriate term of the binomial probability distribution. The slope of the next saw-tooth also has decreased by this same single term. Thus the values at the kth and $(\mathrm{k}+1)$ st local maximum are respectively

$\mathrm{D}[\mathrm{k}] * \sum \quad$ and

$\mathrm{D}[\mathrm{k}+1] * \sum,=\mathrm{D}[\mathrm{k}] * \mathrm{Up} \wedge 2 * \sum$ 
where the sum $\sum$ ' multiplying $\mathrm{D}[\mathrm{k}+1]$ is the same as the sum $\sum$ multiplying $\mathrm{D}[\mathrm{k}]$ except that the first term in the sum is omitted. Hence if the ratio of $\sum$ / $\sum$ multiplied by $\mathrm{Up}^{\wedge} 2$ is greater than one the maximum at the discontinuity has increased while if it is less than one it has decreased. Hence it is critical to examine the behavior of the above ratio $\Sigma$ ' $/ \sum$.

Theorem: Let $\Sigma[\mathrm{k}]$ represent the cumulative distribution function of the binomial probability density with parameter $\mathrm{q}$, where the sum represents the probability of at most $\mathrm{k}$ successes. Then for any value of $\mathrm{q}, 0<\mathrm{q}<1$, the reverse hazard ratio $\sum[\mathrm{k}+1] / \sum[\mathrm{k}]$ is a decreasing function of $\mathrm{k}$. Thus the maximum value of this ratio is $1+\mathrm{n} * \mathrm{q} /(1-\mathrm{q})$ while its minimum value is just $1 /\left(1-q^{\wedge} n\right)$.

Proof: For any discrete probability distribution, a decreasing likelihood ratio implies a decreasing reverse hazard ratio (see Kijima [4] ). But the likelihood ratio for the binomial distribution is just $(n-k) /(k+1) * q /(1-q)$ which clearly is a decreasing function of $\mathrm{k}$ for all values of $\mathrm{q}$ between zero and one. Thus the maximum value is assumed when $\mathrm{k}=0$ and the minimum value is assumed when $\mathrm{k}=\mathrm{n}$.

Now our theorem applies to the binomial distribution with parameter 1-q for which $\sum$ represents the cumulative distribution function ; therefore the ratio $\sum / \Sigma^{\prime}$ is decreasing as $\mathrm{k}$ decreases from $\mathrm{n}$ to zero or increasing as $\mathrm{k}$ increases from zero to $\mathrm{n}$. Therefore the reciprocal ratio $\sum^{\prime} / \sum$ decreases from $1-(1-\mathrm{q})^{\wedge} \mathrm{n}$ (which is slightly less than one) to $1 /(1+n *(1-q) / q$ ) (which is close to zero) as $\mathrm{k}$ increases from zero to $\mathrm{n}$. This decreasing ratio must be multiplied by $\mathrm{Up}^{\wedge} 2$, which is greater than one. The product can thus behave in exactly one of three possible ways.

Case 1: It is always less than one. In this case the saw-tooth maximums are always decreasing and the optimal debt to asset ratio would be zero.

Case 2: It is always greater than one. In this case the saw-tooth maximums are always increasing and the optimal debt to asset ratio would be one.

Case 3: It is initially greater than one but eventually becomes less than one. In this case the saw-tooth function has maximums that successively increase to a point and then successively decrease (it is possible that at the turn around point two successive maximums are equal). In this case there is generally a unique debt to asset ratio between zero and one that yields a maximum value for the expected value of the net present value of the tax savings (there could be two ratios giving the same maximum).

Cases 1 and 2 are impossible for sufficiently large values of the partition $n$. Case 1 requires that $\mathrm{Up}^{\wedge} 2$ multiplied by $1-(1-q)^{\wedge} \mathrm{n}$ must be less than one; but a careful asymptotic analysis of the product reveals that for sufficiently large $n$ the product will be greater than one. Case 2 requires that $\mathrm{Up}^{\wedge} 2$ multiplied by $1 /(1+\mathrm{n} *(1-\mathrm{q}) / \mathrm{q})$ must be greater than one; but the second factor approaches zero as $\mathrm{n}$ approaches infinity while the first factor approaches one so that the product approaches zero..

\section{EXAMPLE}

With parameters $\mathrm{t}=10$ years to maturity, $40 \%$ marginal tax rate, $\Sigma=.20$, assets $=100$, riskless rate of return $\mathrm{R}=0.05$ and $\mathrm{n}=100$ we obtain the result that the optimal debt to equity ratio seems to be at $\mathrm{D}=60$ according to the table on the next page.

\section{CONCLUSION}

Our results would remain true for any sufficiently large partition size; however, the optimal debt to equity ratio will be different. We conjecture that the sequence of optimal debt to equity ratios will converge as the partition size approaches infinity. In any case this methodology should be very useful in guiding a firm towards an optimal choice for its debt to equity ratio. 


\begin{tabular}{|c|c|c|c|}
\hline D & ceil(A) & probability of no default & Expected Value of PVTS \\
\hline 10 & 36 & 1.000 & 4.000 \\
\hline 15 & 39 & 0.997 & 5.982 \\
\hline 20 & 42 & 0.990 & 7.920 \\
\hline 25 & 43 & 0.976 & 11.436 \\
\hline 30 & 45 & 0.953 & 12.880 \\
\hline 35 & 46 & 0.920 & 14.032 \\
\hline 40 & 47 & 0.877 & 14.850 \\
\hline 45 & 48 & 0.825 & 15.320 \\
\hline 50 & 49 & 0.766 & 15.400 \\
\hline 55 & 50 & 0.700 & 16.800 \\
\hline 60 & 50 & 0.700 & 14.404 \\
\hline 65 & 51 & 0.554 & 13.328 \\
\hline 70 & 52 & 0.476 & 14.280 \\
\hline 75 & 52 & 0.476 & 10.144 \\
\hline 85 & 53 & 0.317 & 8.092 \\
\hline
\end{tabular}

\section{REFERENCES}

1. Black, Fisher and Myron Scholes, The Pricing of Options and Corporate Liabilities, J. Political Economy 81 (1973) 637-659.

2. Cox, John C. and Mark Rubinstein, Options Markets, Prentice Hall, Englewood Cliffs, N.J., 1985.

3. Feller, William An Introduction To Probability Theory and Its Applications, John Wiley and Sons, New York, N.Y., 1950.

4. Kijima, Masaaki, Markov Processes for Stochastic Modeling, Chapman and Hall, 1997.

5. Lowenthal, Franklin, Arnold Langsen, and Clark T. Benson, Merton's Partial Differential Equation and Fixed Point Theory, American Mathematical Montly, Vol. 105, No. 5, May 1998, 412-420.

6. Merton, Robert C. Continuous Time Finance, Basil Blackwell, Cambridge, MA, 1990. 
NOTES 